\title{
Aerosols bias daily weather prediction
}

Xin Huang ${ }^{1,2}$, Aijun Ding ${ }^{1,2 *}$

${ }^{1}$ School of Atmospheric Sciences, Nanjing University, Nanjing, 210023, China.

2Jiangsu Provincial Collaborative Innovation Center of Climate Change, Nanjing, 210023, China.

*Aijun Ding Email: dingaj@nju.edu.cn

\section{Keywords}

atmospheric aerosol, daily weather prediction, forecast bias, air temperature, aerosol-radiation interaction

This PDF file includes:

Main Text

Figures 1 to 6

Supporting Information (Figures S1-S10) 


\begin{abstract}
Weather prediction is essential to human daily life. Current numerical weather prediction (NWP) models are still subject to substantial forecast bias and rarely consider the impact of atmospheric aerosols, despite of the consensus of aerosols as the most important sources of uncertainty in predicting climate change. Here we show aerosols as an important driver biasing daily temperature prediction. By using observation minus forecast analysis based on the Global Forecast System and sounding observations, we found that monthly-averaged bias in 24-hour temperature forecast varies between $\pm 1.5^{\circ} \mathrm{C}$ in regions dominated by different types of aerosols. The biases depend on the properties of aerosols over different underlying land surface and on aerosol-cloud interactions over oceans. We also revealed that forecast errors are rapidly magnified with time over regions featuring higher aerosol loadings. Our study provides "direct" evidence of aerosols' impacts on daily weather forecasts and bridges the gaps between weather forecast and climate science regarding the understanding of the impact of atmospheric aerosols.
\end{abstract}

\title{
Main Text Introduction
}

Numerical Weather Prediction (NWP) models, which are performed every day at major operational weather forecast centers, have become the main means for quantitative weather prediction across the globe (1-4). Over the past half-century, NWP models have witnessed substantial progresses leading to increasing weather forecast skill $(2,5,6)$. These advances could be attributed to the steady accumulation of scientific knowledge, particularly the understandings of key processes and their numerical solution/parameterization, and to fast technology development in both data acquisition and data assimilation $(2,3,6)$. Case studies have showed that aerosol is one of the important processes that may influence weather forecast (6-11). In climate models, aerosols have already been well acknowledged as one of the largest sources of uncertainty (12-18). However, the relative importance of the seamless integrated chemistry-meteorology has been less considered in the NWP application than the climate community traditionally $(11,19,20)$ and most current operational NWP models rarely resolve the explicit aerosol processes $(2,11)$. Besides the expensive computational cost, the main cause might be that operational NWP models are highly tuned with more observations in data assimilation, which are considered to potentially fill the gaps of some missing processes like aerosols $(2,11,19,20)$. Here, by conducting an observation minus forecast (OMF) analysis with 3-year daily National Centers for Environmental Prediction (NCEP) Global Forecast System (GFS) data during 2016-2018, we found significantly high bias and expanding forecast errors in daily forecast of lower-tropospheric air temperature in regions with influence from anthropogenic or natural aerosols, indicating aerosols as an important driver biasing daily weather prediction.

\section{Results}

\section{Global distribution of air temperature forecast bias and aerosols}


The OMF analysis provides unique insights into the potential influences from those processes that have not been considered in the models, particularly the time-varied anthropogenic influences (8,21-23). Using daily Global Data Assimilation System (GDAS) analysis and radiosonde data as "observations", respectively, in comparison with NCEP GFS forecast, we calculate the 3-year averaged global distribution of OMF biases in predicted 24-hour lower-tropospheric air temperature (Fig. 1A). Here we chose 24-hour products for the OMF analysis because the 24-hour forecast significantly influences human daily life and features smaller forecast error from various processes in the NWP than a multiday prediction. We mainly focused on $925 \mathrm{hPa}$ as this layer usually represents the upper boundary layer and base of clouds, where air pollutants may influence the boundary dynamics and precipitation (8-10). It shows that, despite of great advances in NWP models and high-performance computing as well as comprehensive observing systems, current NWP models are still subject to notable biases. Well-organized global distribution of strong bias could be well identified from region to region. For example, strong negative biases exist in centralsouthern Africa, Amazon, northern India and eastern China, and positive biases are over the southern Oceans in high latitude of South Hemisphere, the northern Atlantic, Siberia and eastern US. From a global perspective, the positive and negative bias (with monthly means up to $\pm 1.5^{\circ} \mathrm{C}$ ) are almost balanced with each other, resulting an overall weak global mean bias as $-0.03^{\circ} \mathrm{C}$ (Fig. 1A). The spatial pattern of OMF biases coincide with the overall global distribution of aerosols (Fig. 1B), which can be explained by different dominant sources of aerosols, such as sea salts, dust, biomass burning and fossil fuel combustions sources in different regions as shown in fig. S1 (24). The biases exist mainly in the lower-middle troposphere, with signals gradually decreasing with altitude (see fig. S2). Fig. 1A also shows that the radiosonde-GFS bias has consistent spatial distribution but stronger signals in comparison with GDAS-GFS bias (Fig. 1, fig. S3A). Such kind of difference mainly exists below $850 \mathrm{hPa}$ with higher aerosol radiation interaction (see fig. S3BC). It means that even with global available observations assimilated, the model can only capture about half of the bias for the analysis/reanalysis data in the lower troposphere, but for real-time forecast the data assimilation for initial conditions less works in reducing the impacts from aerosols.

\section{Air temperature forecast bias in typical polluted regions}

The maximum positive and minimum negative monthly-averaged biases in air temperature given in Fig. 2 and fig. S4 show more distinct different from region to region. Most of the positive biases exist in spring and winter. The boreal Eurasian continent, i.e. from Europe to Siberia, have particularly strong positive bias (with regional average up to $0.7^{\circ} \mathrm{C}$ ), followed by coastal eastern US and the southern Oceans (Fig. 2, A, C and D, fig. S5). While for the minimum, both central-southern Africa and southeastern Atlantic, and Amazon show stronger negative bias (up to $-1.5^{\circ} \mathrm{C}$ ), followed by northern India and eastern China (see fig. S2B, fig. S5).

The vertical and seasonal distributions of air temperature bias averaged over the main regions (Fig. 2, C and D) clearly demonstrate distinct roles of different types of aerosols in modifying air temperature. Fig. 3 and Fig. 4 present more detailed evidences from the OMF analysis and CALIPSO retrievals on the impact of aerosols on air-temperature forecast bias for Asian continent 
and North America, respectively. Consisted with previous study (22), well-organized and strong negative OMF value (Fig. 3A) could be clearly seen in northern India and Northern-central China in June, the month with minimum negative OMF values (Fig. 2D). The OMF values generally coincide with the horizontal distribution of AOD contributed by anthropogenic emissions (24-26) and also show an overall good negative correlation vertically (Fig. 3BC). However, coastal eastern US is characterized by significantly high positive OMF values correlated to aerosol loadings in March, when biomass burning is active in both Central America and Southeastern US (Fig. 4) (27, 28). The fire smoke containing light-absorbing aerosols may result in the contrast effect on the lower-tropospheric air temperature over the land in southeastern US and the downwind Atlantic Ocean (Fig. 4) (27-28).

Besides the two typical regions, evidences of aerosols' impacts on lower tropospheric air temperature forecast bias in the NWP could also be found for some regions in Fig. 2. For example, a combined effect of smoke over snow cover may well explain the significantly high positive OMF values in boreal Eurasian continent in April (30) (fig. S6). The warming due to dust aerosols over regions downwind both the Sahara and Taklamakan deserts (fig. S7) and dimming effect of smoke aerosols from intensive biomass burning and a possible interaction with clouds in Africa (fig. S8) in typical seasons, which have been extensively studied (26, 29-32), could be well identified by the OMF analysis. For the Amazon region, a minimum negative OMF bias in August and September (Fig. 2) indicates a possible impact from smoke-induced cloud condensation nuclei (CCN), even the averaged AOD is not as high as other polluted regions (33) (Fig. 1 and Fig.2).

Although our results are generally consistent with previous works on aerosols radiative forcing and their impact on regional climate in these regions, it should be noted that the OMF analysis here is derived from numerical weather forecast rather than simulations using a model with comprehensive description of aerosols and meteorology-chemistry coupling. These results demonstrate that the "simple" OMF analysis, which is conducted for different regions and different seasons using a unified method, can provide unique insights into the impact from the missing processes, like aerosols, on weather forecast and regional climate from a global perspective. However, more detailed and quantitative understandings of how the different aerosols influences the lowertropospheric air temperature in different regions, especially from the aerosol-radiation interaction $(\mathrm{ARI})$ and aerosol-cloud interaction (ACl) need more modeling efforts in the future.

\section{Impacts of cloud cover and underlying surface}

Since the impact of aerosols on air temperature, from both direct and indirect effects, all depends on solar radiation, we use aerosol optical depth (AOD) multiple shortwave radiation (SW) as a proxy (denoted as $A O D \times S W$ ) to investigate the relationship of aerosols with air temperature biases as well as other relevant processes, e.g. the underlying surface and clouds, that may influence the aerosol-radiation interaction $(5,15)$. Fig. $5 \mathrm{~A}$ suggests that the air-temperature bias over land generally show in-phase change with surface albedo, i.e. the darker the stronger (see fig. S9). These results indicate the hybrid and interlinked effects of aerosols and land-use/land cover change, which have usually been studied separately (18) and sometime might also be mis-understood. For 
example, previous studies usually attributed the OMF or Observation minus Reanalysis (OMR) bias to land-surface process, e.g. urbanization, alone $(23,34)$.

Over ocean, the warm bias exists mainly over regions with strong wind speed (ws>15 m-1) (Fig. 5C), which cause more emission of wind-blow sea-salt aerosols (24) (fig. S1). Fig. 3C also shows that the air temperature bias from strong wind speed slightly decreases as AOD $\times S W$ proxy, indicating a change of regimes from aerosol-cloud interaction to aerosol-radiation interaction under increasing concentration of sea-salt aerosol $(16,24,35)$. Fig. $5 \mathrm{C}$ also shows negative air temperature bias with large error bars for low clouds over ocean. The scatter plot of bias in column cloud water below $500 \mathrm{hPa}$ versus that in air temperature clearly demonstrates a strong relation for cloud top below $850 \mathrm{hPa}$ : increased cloud water associated with significant decrease in air temperature (Fig. 5D). In fact, the enhanced cloud water mainly exists over regions downwind intensive biomass burning smoke like southeastern Atlantic and subtropical Asia, where the smoke aloft induced semi-direct effects enhance low cloud and dim the lower troposphere air temperature (Fig. 2B, fig. S8D) $(13,31,32)$. In contrast, the cloud bias over land shows less relationship with air temperature bias (Fig. 5B), indicting a dominate role of aerosol-radiation interaction (see Fig. $3 A)$.

\section{Bias magnification with prediction time}

The above analysis based on 24-hour NWP modeling results clearly demonstrate the impact of aerosols in modifying daily air temperature forecast over many regions around the globe. Nowadays, people usually pay attention to weather prediction with a time window for 3-5 days even longer. Fig. 6 shows that the bias in air temperature prediction under high aerosol conditions are statistically greater than those under clean circumstance. Fast expanded forecast errors exist in the northern India and eastern China with intense haze pollution from fossil fuel combustion sources (8, 9) (Fig. 6B), in Africa and Amazon with intensive biomass burning (31,32) (Fig. 6, C-E). A significantly higher and increasing root mean square error with forecast time can be clearly seen from regions with higher aerosol loading than regions with less aerosols (Fig. 6F). Such kind of increasing bias in predicted air temperature with forecast time could also be seen globally over main land and ocean areas (fig. S10). These mean that aerosols not only bias the air temperature, but also add more uncertainty and cause poor predictability in weather forecast in regions with high aerosol loading, where characterization of aerosol processes, either anthropogenic haze pollution or natural emitted aerosols, become one the key challenges in NWP models for raising the skills of multi-day weather prediction. It should be pointed out that these regions with high aerosol loading are usually with high population (e.g. Asian countries) or fragile ecosystem/agricultural field (e.g. arid and semi-arid region in Africa and central Eurasia). The weaker predictability of weather in these regions should have more impacts to human daily life.

For the predictability, Fig. $6 \mathrm{C}$ suggests a generally linear change of biases with forecast time and fig. S10 shows that except for an increased amplitude, the spatial pattern of air temperature bias was less changed with forecast time. These indicate that the bias mainly caused local aerosol radiation interaction and the forecast error is less propagated to downwind regions. This is good 
news for a practical improvement of numerical weather prediction. Since the bias overall has good correlation with aerosols under a specific underlying surface or cloud regime, the application of new technologies, like artificial intelligence (36), may help reduce the bias and improve the overall skills of weather forecast.

\section{Discussion}

Here our analysis demonstrate that the current state-of-the-art NWP models still have large discrepancy in forecast of tropospheric air temperature in many regions with different type of aerosols, despite of a revolution of NWP models achieved due to improved knowledge, fast development of high-performance computers, and comprehensive observations available for data assimilation. The biases in air temperature are different in vertical profiles and also in seasonal variations for different type of aerosols over different underlying surface. In general, the dimming effect of aerosols occurs in regions with high aerosol loading over land, e.g. significantly high anthropogenic aerosols in India and China and heavy smoke and dust in Africa, or regions with strong aerosol-cloud interactions, e.g. the smoky Amazon and the biomass burning-enhanced low cloud in Southern Atlantic Ocean. The warming effects of aerosols are more complex, especially in remote areas and oceans, where either the effect of ARI or of ACl could be important. The warming regions identified by OMF analysis included eastern US mainly influenced by biomass burning, and boreal Eurasian continent with smoke aerosols over snow surface in spring, downwind Sahara and Taklamakan Deserts, and Southern Oceans linked with a possible impact from aerosol-cloud-interaction of sea salt.

To minimize these biases, more measurements, including those from radiosonde observation and improved satellite retrievals in the lower troposphere, should be added in these regions.

Considering air temperature is a principle meteorological parameter, which influences advection, convection, boundary layer dynamics and cloud formation $(8,11)$, the aerosols-induced air temperature biases should be very important for the prediction of other meteorological parameters, e.g. precipitation and even wind circulations. To improve the overall forecast skills in different regions around the globe concerns the influences from aerosols, new technologies like deep learning are potentially good means to reduce the bias, but long-termly the finally solution is to develop and apply operational NWP models fully characterizing the physical and chemical processes of aerosols and their coupling with detailed characterization of their spatiotemporal variations.

\section{Materials and Methods}

\section{Radiosonde observations}

Integrated Global Radiosonde Archive (IGRA), a radiosonde dataset from the National Climatic Data Center (NCDC), consists of radiosonde and pilot balloon observations at over 2700 globally distributed stations. The earliest data date back to 1905, and recent data become available in near real time. Since 1958, the World Meteorological Organization (WMO) has prescribed that 
soundings be taken around 0000 UTC and 1200 UTC each day. This dataset is well qualityassured since that the quality assurance algorithms check for format problems, physically implausible values, internal inconsistencies among variables, runs of values across soundings and levels, climatological outliers, and temporal and vertical inconsistencies in temperature (37). Observations are available at standard and variable pressure levels, fixed- and variable-height wind levels, and the surface and tropopause. Variables include pressure, temperature, geopotential height, relative humidity, dew point depression, etc. The mandatory pressure levels for measurements are $1000,925,850$, and $700 \mathrm{hPa}$ for the lower troposphere, which are specified by WMO. Then, disparities between radiosonde observations and GFS forecast could provide some clue to poorly-resolved processes in the model, so do the gaps between analysis and forecast data.

\section{Global forecast and analysis data}

We collected 3-year global forecast and analysis temperature and cloud data from Global Forecast System (GFS), which is a weather forecast model produced by the National Centers for Environmental Prediction (NCEP) and has been in the United States' National Weather Service (NWS) operations since 1980. The NCEP operational GFS has applied finer resolution with analysis and forecast grids are on a 0.25 by 0.25 global latitude longitude grid since 2015 and is archived at Research Data Archive at the National Center for Atmospheric Research, Computational and Information Systems Laboratory. The analysis uses myriad observations at specific locations or on an irregular grid to produce a representation of the atmospheric state over the GFS model grid, which has included statistical measures of both the variability of the measurements and of the atmosphere itself (38). Since the year of 2012, NCEP GFS operational Global Data Assimilation System (GDAS) has transitioned to a 3DVar based ensemble-variational (3DEnsVar) hybrid data assimilation system. Existing studies have shown that each data assimilation cycle in GFS generally incorporates more than 25000 radiosonde observations, which has been indicated to most significantly impact the analysis accuracy, particularly for air temperature (39). By using the analysis as the starting point, GFS physical forecast models then propagate an atmospheric state forward in time. In this study, we adopted 24-hour, 48-hour, 72 hour, 96-hour and 120-hour forecast to evaluate the model performance with forecast time.

\section{Other observations or data}

The GFS model has not well resolved the impact of atmospheric chemistry on physical processes yet, and aerosols' radiative forcing has been found to play a vital role in meteorology and climate. Since lacking of seamless integrated chemistry-meteorology modeling, GFS forecast biases were compared with global emission inventories and satellite retrievals on aerosol. Here, the MACCity (MACC/CityZEN EU projects) emissions dataset was applied for demonstrate anthropogenic emissions, and emission intensity from biomass burning was obtain from the Global Fire Emissions Database (GFEDv4, Version 4.1) (40). The monthly spatial distribution of aerosol optical depth were provided by Multi-angle Imaging SpectroRadiometer (MISR) product. The vertical profile of aerosol extinction and cloud occurrence were derived from Cloud-Aerosol Lidar and Infrared Pathfinder Satellite Observations (CALIPSO) level 3 aerosol product48. The spatial distribution of land cover and snow cover were derived from Moderate Resolution Imaging Spectroradiometer (MODIS) land cover (MCD12C1) and snow retrievals (MYD10), respectively. For the calculation of $A O D \times S W$ proxy, shortwave radiation (SW) with the wavelength ranging from 0.4 to $4.5 \mu \mathrm{m}$ was 
provided by Clouds and the Earth's Radiant Energy System (CERES) Edition 4.0 (Ed4) Energy Balanced and Filled (EBAF)-surface data product.

\section{Acknowledgments}

The work is supported by National Natural Science Foundation of China (41725020 and 41922038). We are grateful to NCEP GFS to make the GFS forecast data and GDAS analysis data publicly available. The radiosonde observations are archived at Integrated Global Radiosonde Archive (IGRA, ftp://ftp.ncdc.noaa.gov/pub/data/igra). Global forecast and analysis data produced by the National Centers for Environmental Prediction is available at https://rda.ucar.edu/datasets/ds084.1. MISR, MODIS and CALIPSO retrievals are openly available and can be accessed via https://earthdata.nass.gov and https://eosweb.larc.nass.gov. The radiation flux data (CERES_EBAF) is archived at https://ceres.larc.nasa.gov/. We thank the High-Performance Computing \& Massive Data Center (HPC\&MDC) of School of Atmospheric Science, Nanjing University for doing the numerical calculations in this paper on its Blade cluster system.

\section{References}

1. Environmental Modeling Center National Centers for Environmental Prediction Office, The GFS atmospheric model. Note 442, 14 (2003).

2. P. Bauer, A. Thorpe, G. Brunet, The quiet revolution of numerical weather prediction. Nature 525, 47-55 (2015).

3. S. G. Benjamin et al., 100 years of progress in forecasting and NWP applications. Meteorological Monographs 59, 13.11-13.67 (2019).

4. Hollingsworth et al., Toward a monitoring and forecasting system for atmospheric composition: The GEMS project. B Am Meteorol Soc 89, 1147-1164 (2008).

5. J. Dudhia, A history of mesoscale model development. Asia-Pac J Atmos Sci 50, 121-131 (2014).

6. S.-Y. Hong, J. J. B. o. t. A. M. S. Dudhia, Next-generation numerical weather prediction: Bridging parameterization, explicit clouds, and large eddies. B Am Meteorol Soc 93, ES6ES9 (2012).

7. J. M. Creamean et al., Dust and Biological Aerosols from the Sahara and Asia Influence Precipitation in the Western U.S. Science 339, 1572-1578 (2013).

8. A. J. Ding et al., Intense atmospheric pollution modifies weather: a case of mixed biomass burning with fossil fuel combustion pollution in eastern China. Atmos Chem Phys 13, 1054510554 (2013).

9. J. W. Fan et al., Substantial contribution of anthropogenic air pollution to catastrophic floods in Southwest China. Geophys Res Lett 42, 6066-6075 (2015).

10. P. E. Saide et al., Central American biomass burning smoke can increase tornado severity in the US. Geophys Res Lett 42, 956-965 (2015).

11. A. Baklanov et al., Key Issues for Seamless Integrated Chemistry-Meteorology Modeling. $B$ Am Meteorol Soc 98, 2285-2292 (2017). 
12. K. S. Carslaw et al., Large contribution of natural aerosols to uncertainty in indirect forcing. Nature 503, 67-71 (2013).

13. D. Koch, A. D. Del Genio, Black carbon semi-direct effects on cloud cover: review and synthesis. Atmos Chem Phys 10, 7685-7696 (2010).

14. I. Koren, J. V. Martins, L. A. Remer, H. Afargan, Smoke invigoration versus inhibition of clouds over the Amazon. Science 321, 946-949 (2008).

15. V. Ramanathan, P. J. Crutzen, J. T. Kiehl, D. Rosenfeld, Aerosols, climate, and the hydrological cycle. Science 294, 2119-2124 (2001).

16. D. Rosenfeld et al., Aerosol-driven droplet concentrations dominate coverage and water of oceanic low-level clouds. Science 363, 599 (2019).

17. J. H. Seinfeld et al., Improving our fundamental understanding of the role of aerosol-cloud interactions in the climate system. P Natl Acad Sci USA 113, 5781-5790 (2016).

18. T. F. Stocker et al., Climate change 2013: The physical science basis. (2013).

19. A. Baklanov et al., Online coupled regional meteorology chemistry models in Europe: current status and prospects. Atmos Chem Phys 14, 317-398 (2014).

20. G. Grell, A. Baklanov, Integrated modeling for forecasting weather and air quality: A call for fully coupled approaches. Atmos Environ 45, 6845-6851 (2011).

21. M. Dahoui, L. Isaksen, G. J. E. N. Radnoti, Assessing the Impact of Observations Using Observation-minus-forecast Residuals. ECMWF Newsletter 27-31 (2017).

22. X. Huang, Z. L. Wang, A. J. Ding, Impact of Aerosol-PBL Interaction on Haze Pollution: Multiyear Observational Evidences in North China. Geophys Res Lett 45, 8596-8603 (2018).

23. E. Kalnay, M. Cai, Impact of urbanization and land-use change on climate (vol 423, pg 528, 2003). Nature 425, 102-102 (2003).

24. M. Chin et al., Light absorption by pollution, dust, and biomass burning aerosols: a global model study and evaluation with AERONET measurements. Ann Geophys-Germany 27, 3439-3464 (2009).

25. Z. Q. Li et al., Aerosol and monsoon climate interactions over Asia. Rev Geophys 54, 866929 (2016).

26. H. B. Yu et al., Direct radiative effect of aerosols as determined from a combination of MODIS retrievals and GOCART simulations. J Geophys Res-Atmos 109 (2004).

27. J. Wang, S. A. Christopher, Mesoscale modeling of Central American smoke transport to the United States: 2. Smoke radiative impact on regional surface energy budget and boundary layer evolution, J. Geophy. Res. 111, D14S92 (2006).

28. Huang, R. et al., Burned area comparisons between prescribed burning permits in Southeastern United States and two satellite-derived products, J Geophys Res - Atmos 123, 9, 4746-4757 (2018).

29. Y. J. Kaufman, I. Koren, L. A. Remer, D. Rosenfeld, Y. Rudich, The effect of smoke, dust, and pollution aerosol on shallow cloud development over the Atlantic Ocean. P Natl Acad Sci USA 102, 11207-11212 (2005).

30. J. Hansen, L. Nazarenko, Soot climate forcing via snow and ice albedos. P Natl Acad Sci USA 101, 423-428 (2004). 
31. Z. Lu et al., Biomass smoke from southern Africa can significantly enhance the brightness of stratocumulus over the southeastern Atlantic Ocean. P Natl Acad Sci USA 115, 2924-2929 (2018).

32. P. Zuidema et al., Smoke and Clouds above the Southeast Atlantic Upcoming Field Campaigns Probe Absorbing Aerosol's Impact on Climate. B Am Meteorol Soc 97, 11311135 (2016).

33. Andreae, M.O. Correlation between cloud condensation nuclei concentration and aerosol optical thickness in remote and polluted regions, Atmos Chem Phys, 99, 543-556 (2009).

34. M. Cai, E. Kalnay, Can reanalysis have anthropogenic climate trends without model forcing? J Climate 18, 1844-1849 (2005).

35. D. Rosenfeld, S. Sherwood, R. Wood, L. Donner, Climate Effects of Aerosol-Cloud Interactions. Science 343, 379-380 (2014).

36. M. Reichstein et al., Deep learning and process understanding for data-driven Earth system science. Nature 566, 195-204 (2019).

37. I. Durre, R. S. Vose, D. B. Wuertz, Overview of the Integrated Global Radiosonde Archive. J Climate 19, 53-68 (2006).

38. J. S. Whitaker, T. M. Hamill, X. Wei, Y. C. Song, Z. Toth, Ensemble data assimilation with the NCEP Global Forecast System. Mon Weather Rev 136, 463-482 (2008).

39. G. Kutty, X. G. Wang, A Comparison of the Impacts of Radiosonde and AMSU Radiance Observations in GSI Based 3DEnsVar and 3DVar Data Assimilation Systems for NCEP GFS. Adv Meteorol (2015).

40. G. R. van der Werf et al., Global fire emissions estimates during 1997-2016. Earth Syst Sci Data 9, 697-720 (2017). 
Figures and Tables

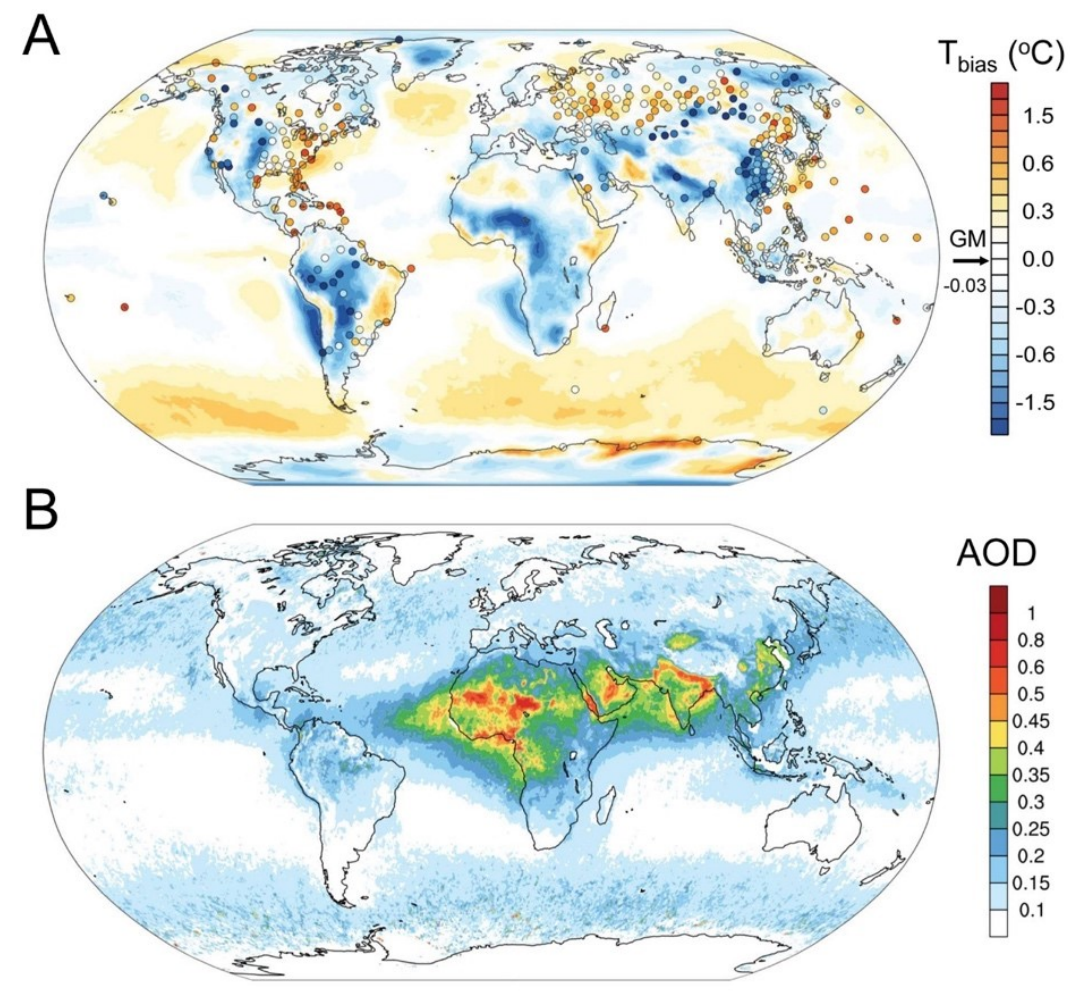

Figure 1. Global distribution of air temperature forecast bias and aerosols. (A) Averaged 925 $\mathrm{hPa}$ Observation minus Forecast (OMF) air temperature bias for GFS 24-hour forecast compared with GDAS analysis (GDAS-GFS, shaded contour) and radiosonde observations (RadiosondeGFS, circles) during 2016-2018. The global mean forecast bias (GM) is labeled at the color bar. (B) Global distribution of averaged MISR aerosol optical depth (AOD) during 2016-2018. 


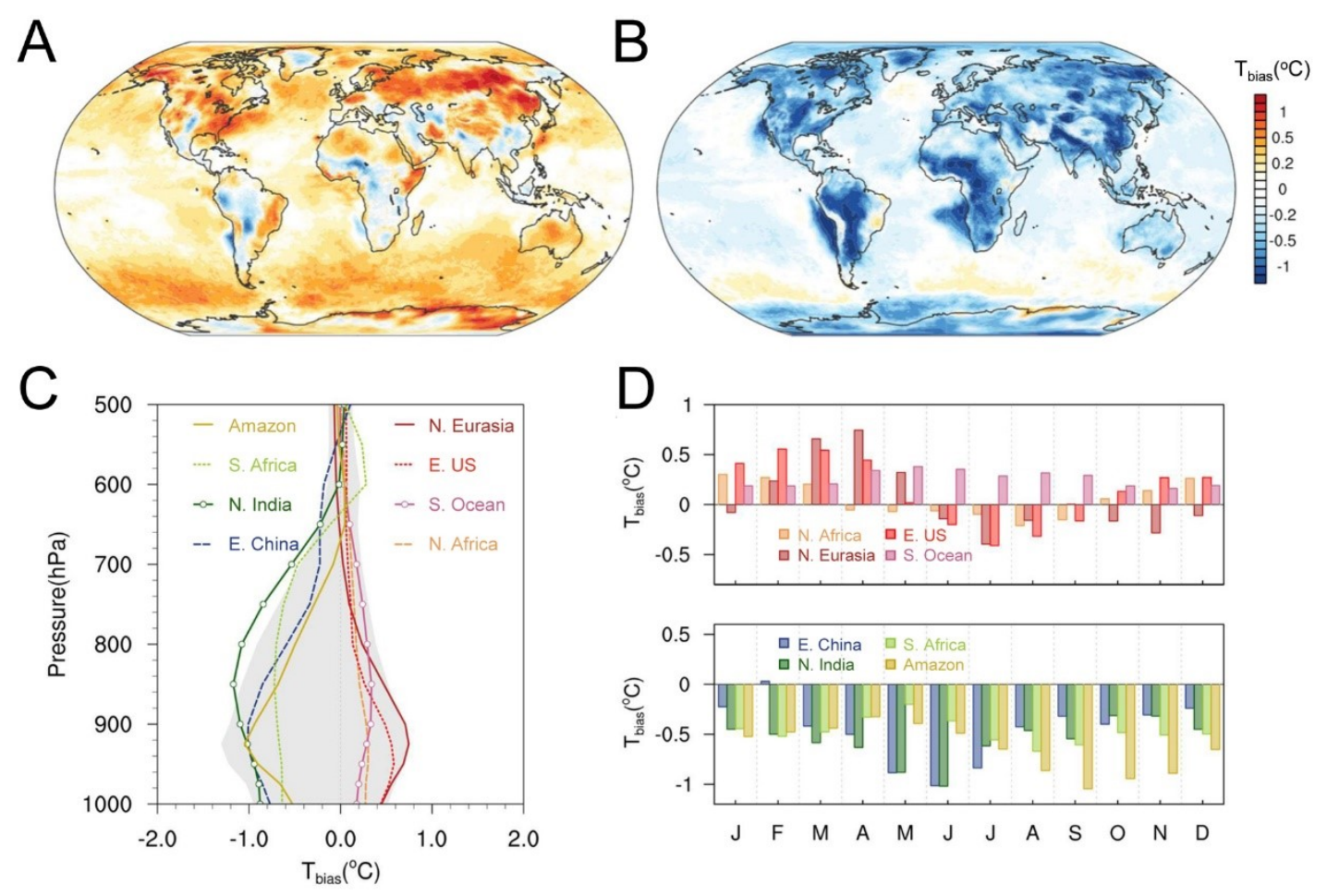

Figure 2. Regional difference in maximum positive and minimum negative monthly-averaged air-temperature bias. (A) Maximum (positive) and (B) minimum (negative) monthly-mean OMF bias (GDAS-GFS) in 24-hour air temperature forecast at 925Pa. (C) Vertical profiles of OMF air temperature bias (GDAS-GFS) in 24-hour forecast for typical regions with different type of aerosols (Regions are defined in Fig. S6). (D) Seasonal variations of regional-averaged OMF temperature bias (GDAS-GFS) in 24-hour forecast in typical regions. 

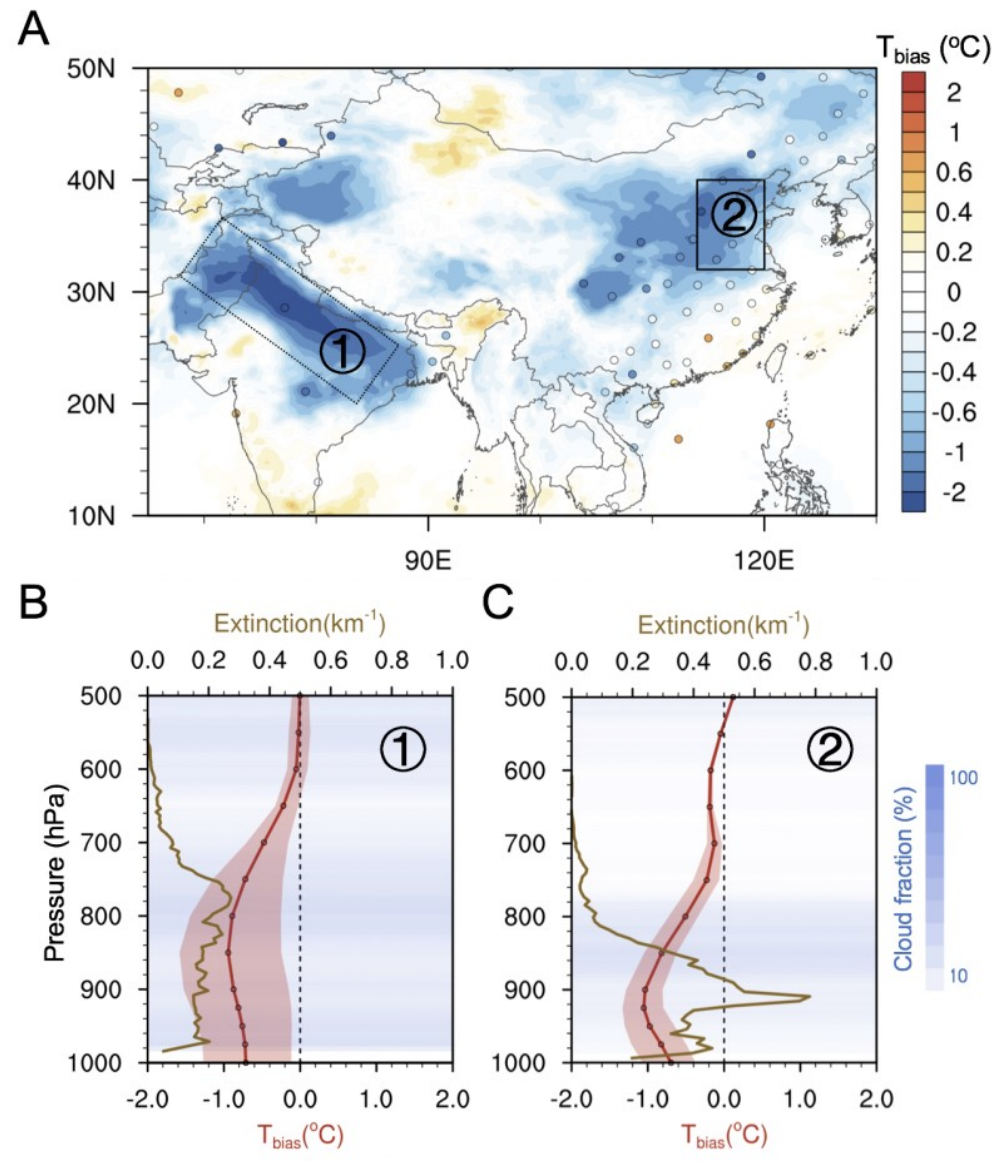

Figure 3. Dimming effect induced by anthropogenic aerosols in India and China. (A) Spatial distribution of OMF air temperature bias between GFS 24-hour forecast and GDAS analysis at 925 $\mathrm{hPa}$ in Asia in June with minimum negative air-temperature forecast bias. Vertical profiles of temperature forecast bias, aerosol extinction and cloud fraction retrieved by CALIPSO in (B) northern India and (C) eastern China. 


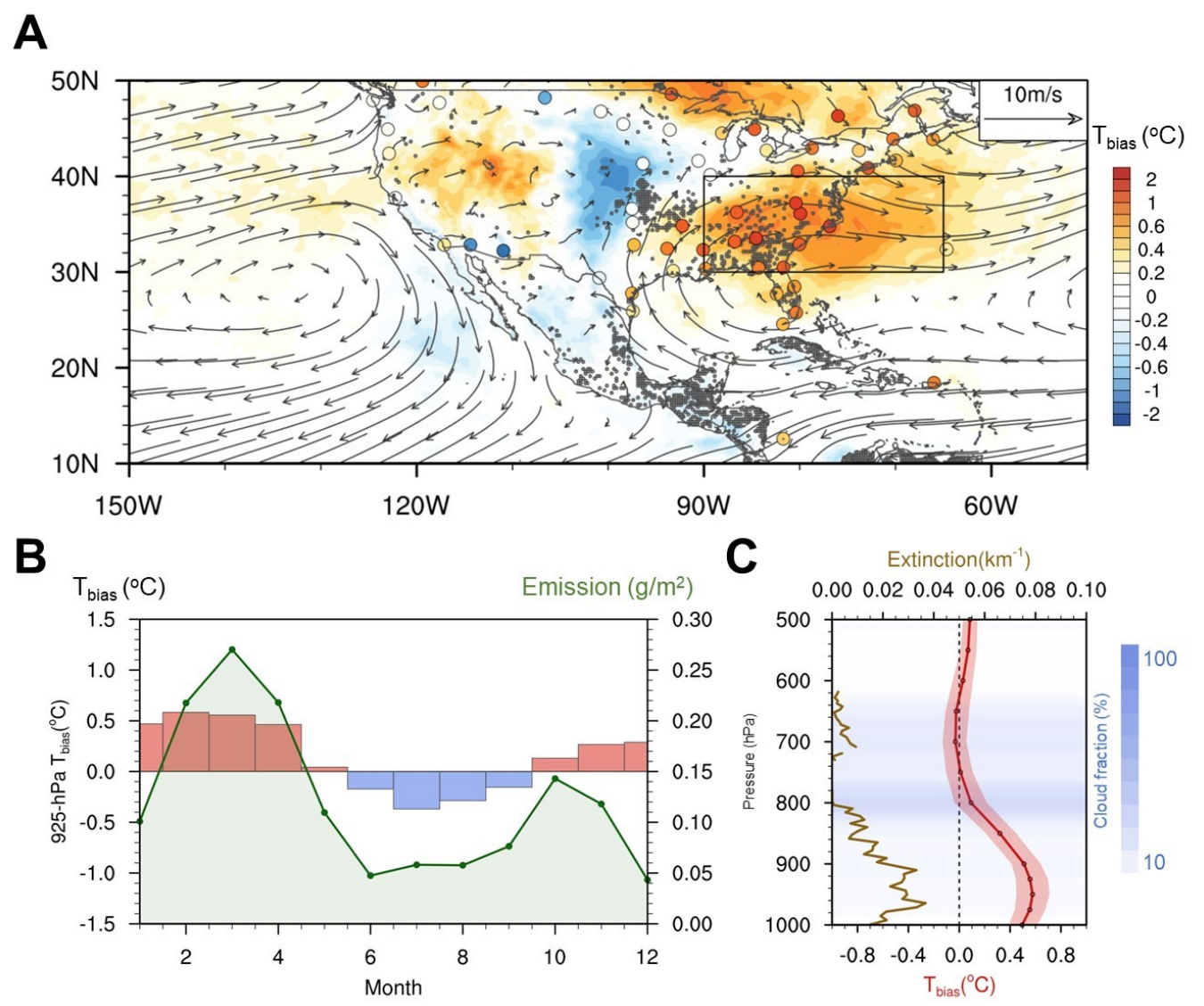

Figure 4. Impact of biomass burning aerosols on the warming effects in eastern US in March. (A) Spatial distribution of averaged OMF air temperature biases of GFS 24-hour from GDAS analysis, radiosonde observations and wind vector at $925 \mathrm{hPa}$ in North America for March in 20162018. (B) Monthly variations of $925 \mathrm{hPa}$ OMF temperature forecast bias and biomass burning emission (grey dots mark carbon emission rate greater than $\mathrm{g} / \mathrm{m}^{2} / \mathrm{month}$ ) in East US (black rectangle in A). (C) Vertical profiles of temperature forecast bias, aerosol extinction and cloud fraction retrieved by CALIPSO in the corresponding region in March during 2016-2018. 

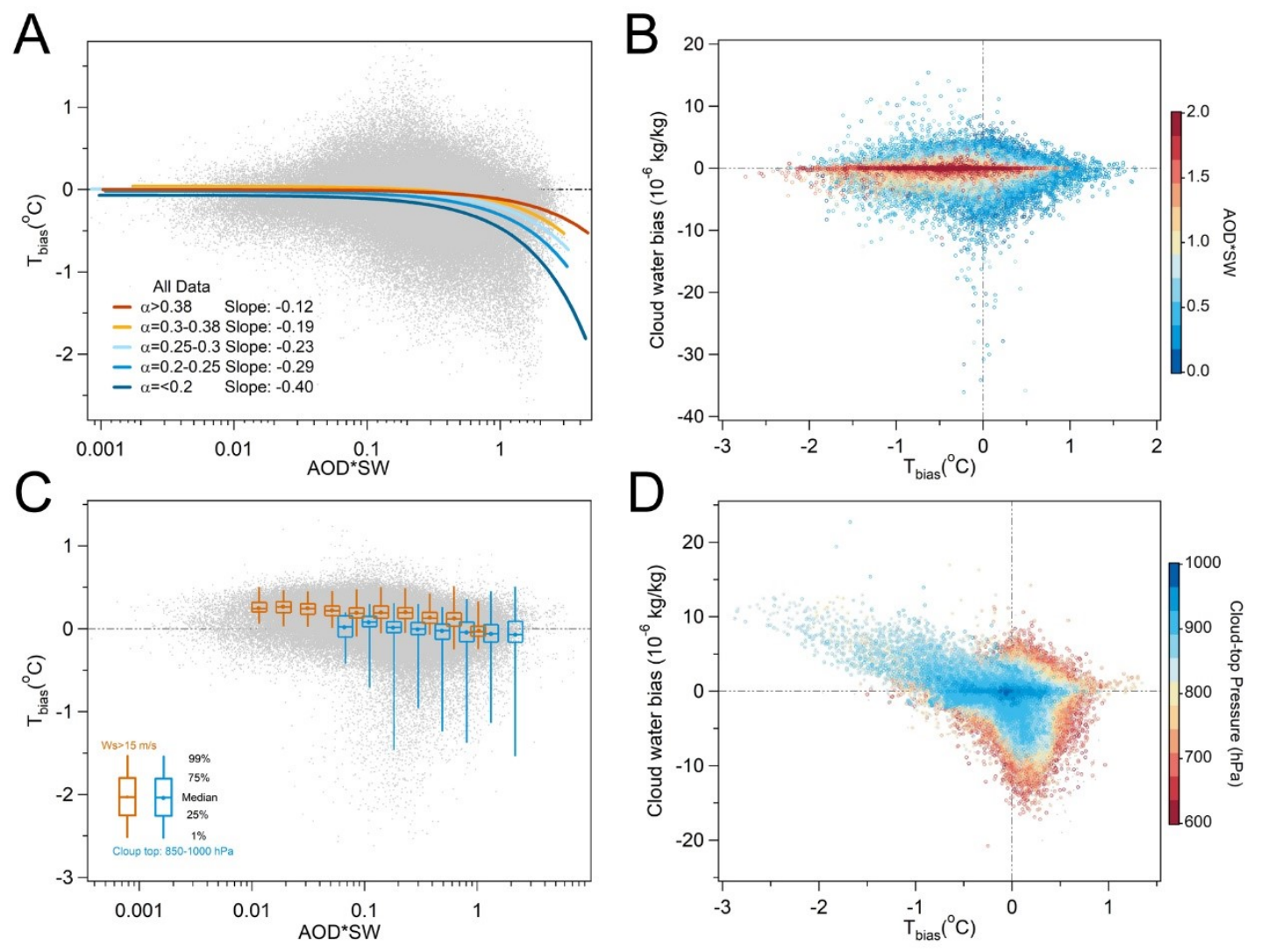

Figure 5. Relationship of air temperature bias with main factors over land and sea. (A) 925 $\mathrm{hPa}$ OMF air temperature bias (GDAS-GFS) as a function of the aerosol-radiative proxy, Aerosol Optical Depth multiple short-wave radiation $(A O D \times S W)$, over land. Liner fittings for data with different albedo a. (B) OMF bias (GDAS-GFS) in column cloud water below $500 \mathrm{hPa}$ as a function of OMF temperature bias at $925 \mathrm{hPa}$ over land, color-coded with AOD $\times$ SW. (C) Same as A but for ocean. Brown and blue box-whisker plots show data with wind speed over $15 \mathrm{~m} \mathrm{~s}-1$ and cloud top below $850 \mathrm{hPa}$, respectively. (D) Same as B but for data over ocean, color-coded with the cloudtop pressure. 

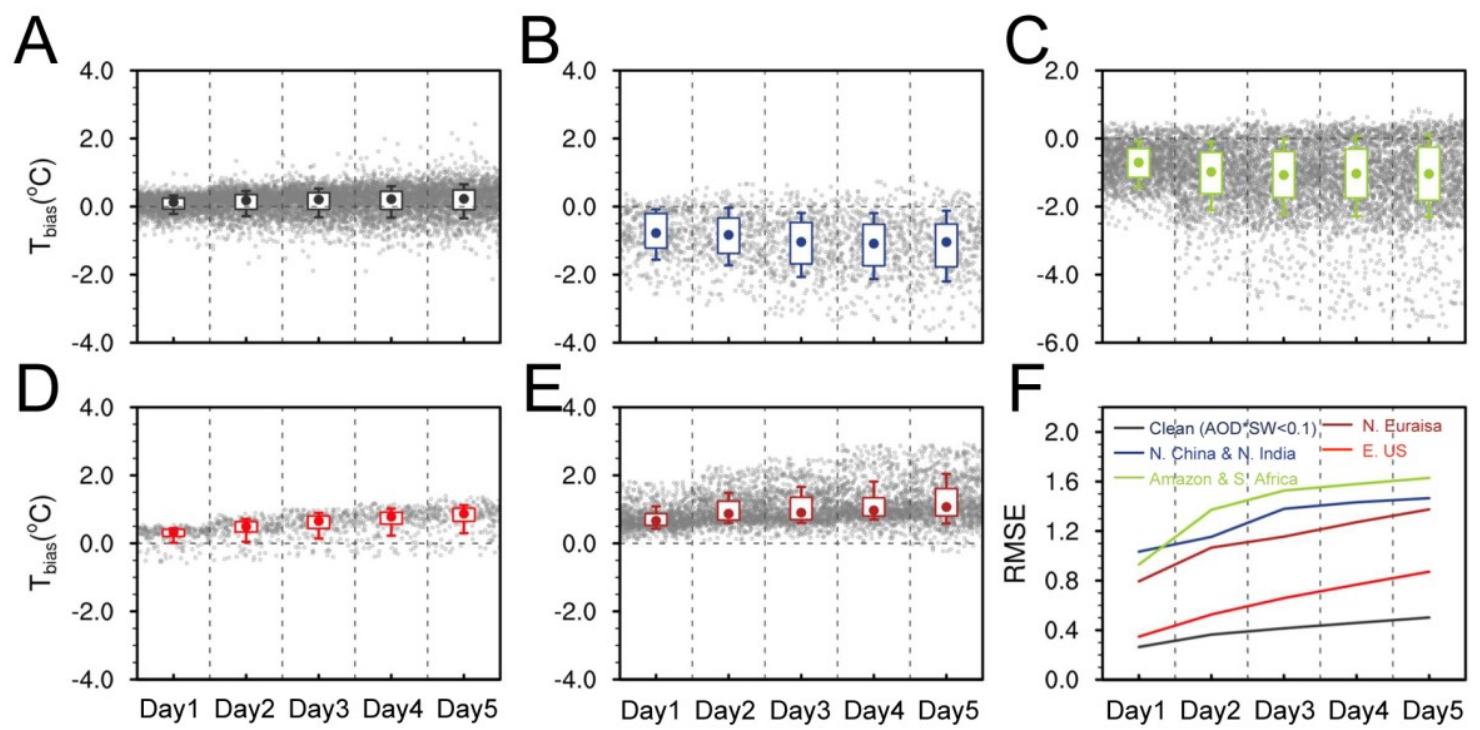

Figure 6. Increasing biases with prediction time in high aerosol regions. 925-hPa OMF air temperature biases of 1-5 days prediction in different regions: $(\mathbf{A})$ clean land area with $A O D \times S W$ less than $0.1,(B)$ regions with significant anthropogenic pollution including northern China and northern India, (C) regions substantially influenced by biomass burning smoke like southern Africa and Amazon, (D) eastern US, and (E) northern Eurasia. (F) Time series of root mean square error (RMSE) of air temperature forecast in GFS in comparison to GDAS in regions as (A-E). Note that here we show the forecast biases at every 24-hour interval of prediction time, and the grey dots in each column correspond to the same prediction time in all the subplot. 


\section{Supplementary Information}
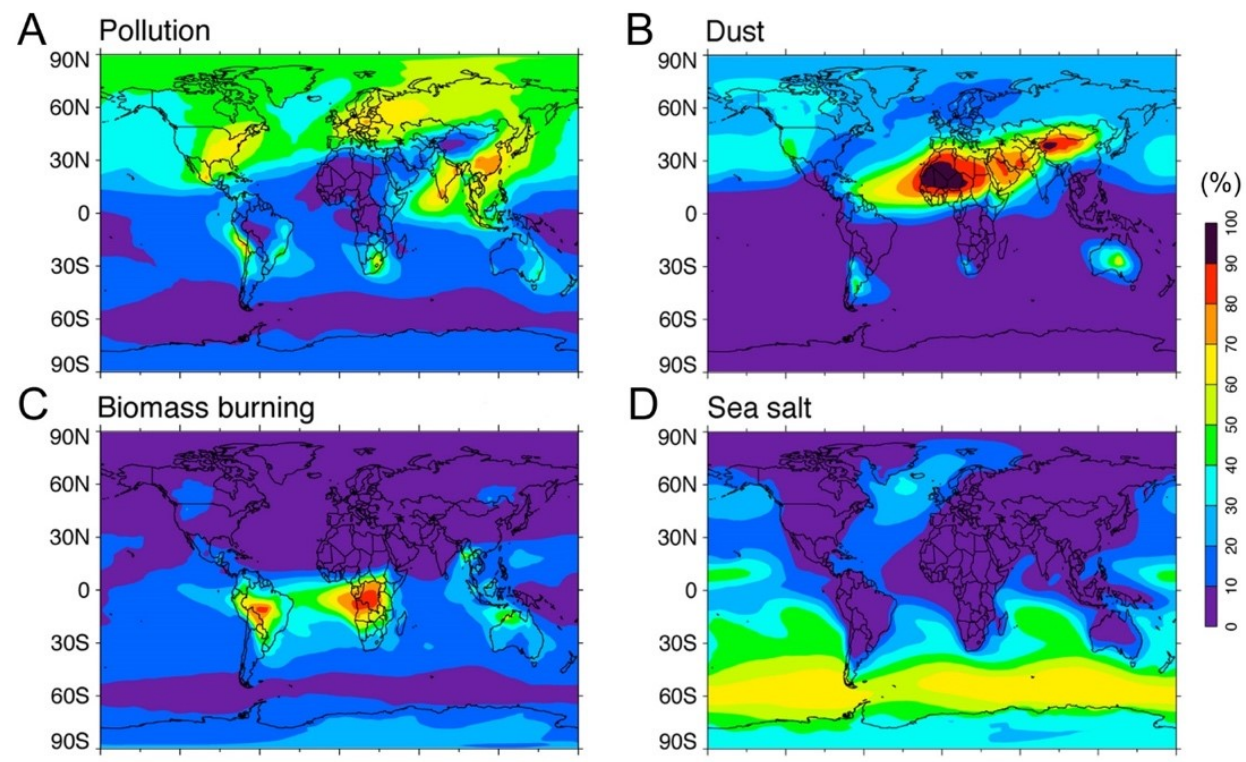

Fig. S1 Global distribution of aerosols. Percentage contributions to $550 \mathrm{~nm}$ AOD from a, pollution; b, dust; c, biomass burning; d, sea salt based on the Goddard Chemistry Aerosol Radiation and Transport (GOCART) model simulations (24). 


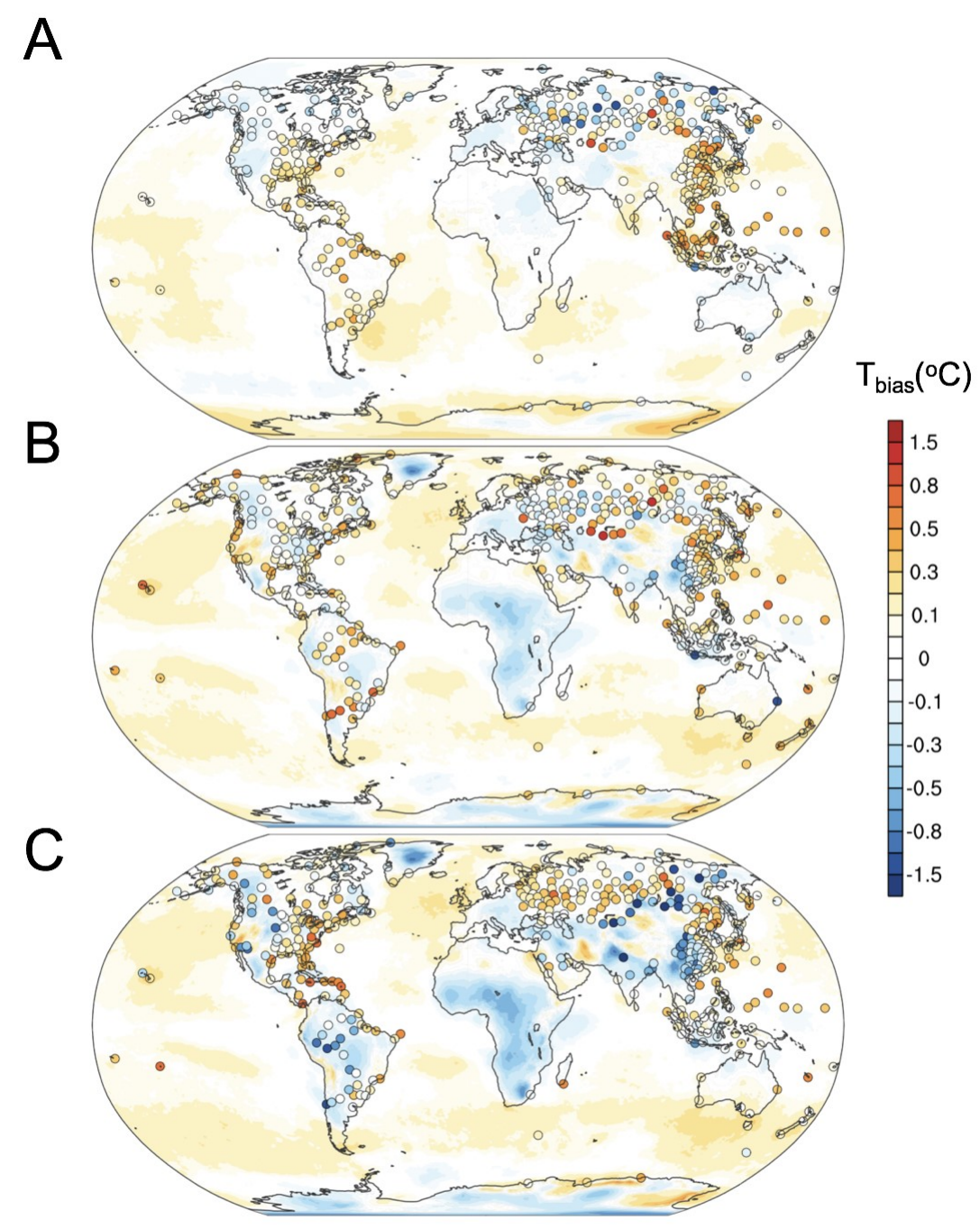

Fig. S2 Global distribution of OMF temperature bias at different pressure levels. Averaged OMF air temperature bias for GFS 24-hour forecast compared with GDAS analysis (GDAS-GFS, shaded contour) and radiosonde observations (Radiosonde-GFS, circles) at (A) $500 \mathrm{hPa}$; (B) 700 hPa; (C) 850 hPa respectively, during 2016-2018. 


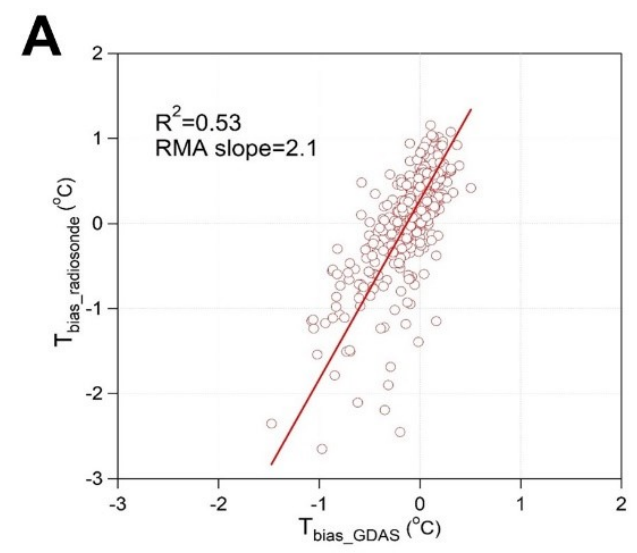

B
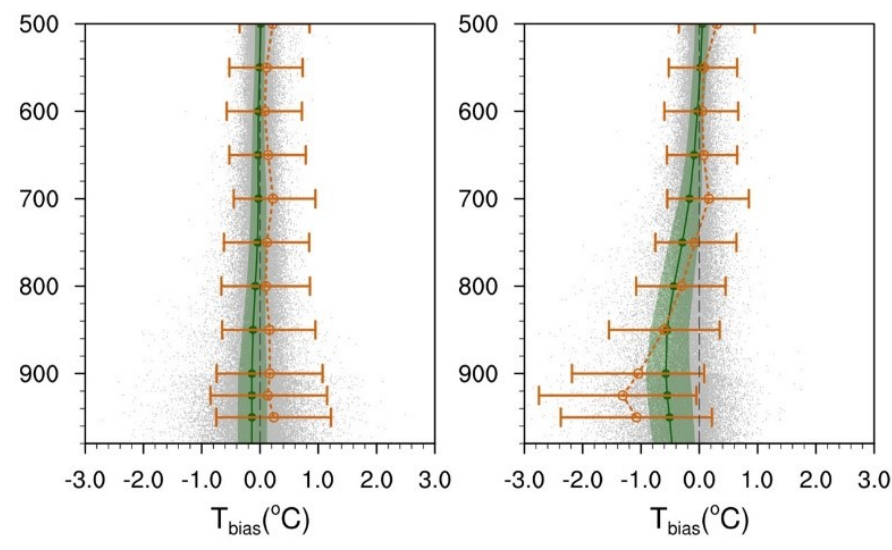

Fig. S3 Comparison of OMF bias for radiosonde and GDAS as observations. (A) Scatter plot of OMF 24-hour air temperature bias at $925 \mathrm{hPa}$ compared with that from radiosonde observations (Radiosonde-GFS) and from corresponding analysis data (GDAS-GFS), respectively. (B) Vertical profile of 24-hour air temperature forecast bias compared with radiosonde observations over land when $A O D \times S W$ is less than 1.0. (C) Vertical profile of 24-hour temperature forecast bias compared with radiosonde observations over land when AOD $\times S W$ greater than 1.0. Green and orange lines present biases from radiosonde observations and corresponding analysis data, respectively. Shadows and bars represent $25-75^{\text {th }}$ percentile ranges. 
A

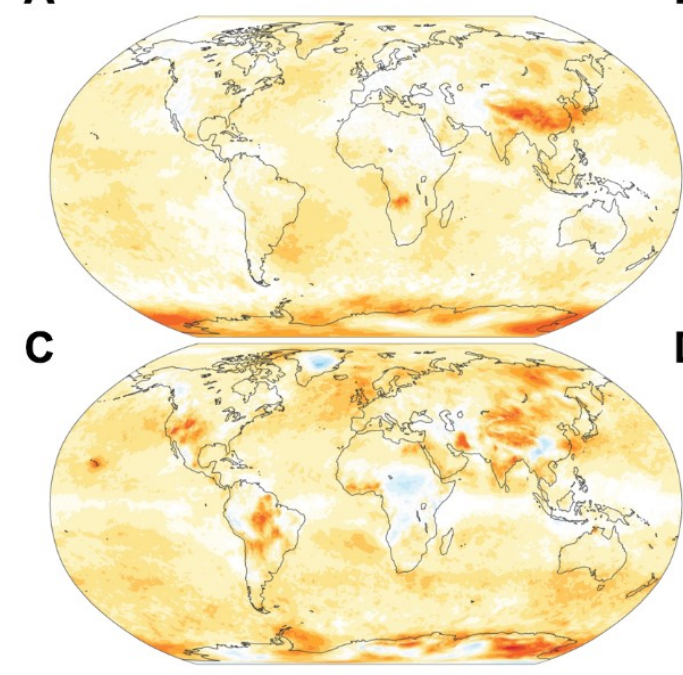

B

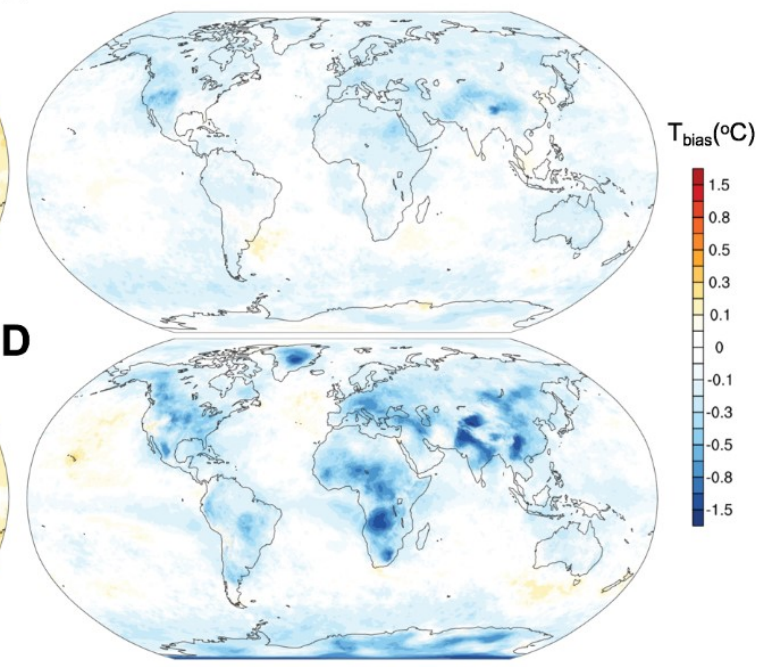

Fig. S4 Maximum positive and minimum negative monthly-averaged air temperature bias at different altitudes. Maximum positive (A, C) and negative (B, D) monthly air temperature bias of GFS 24-hour forecast compared with GDAS analysis at 500 and $700 \mathrm{hPa}$, respectively. 
A

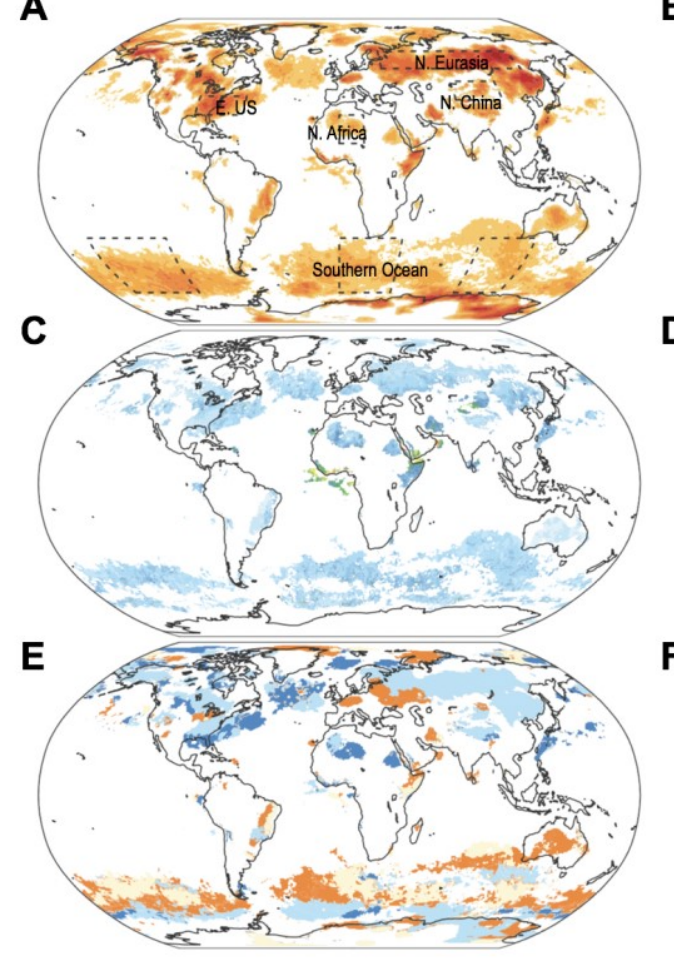

B

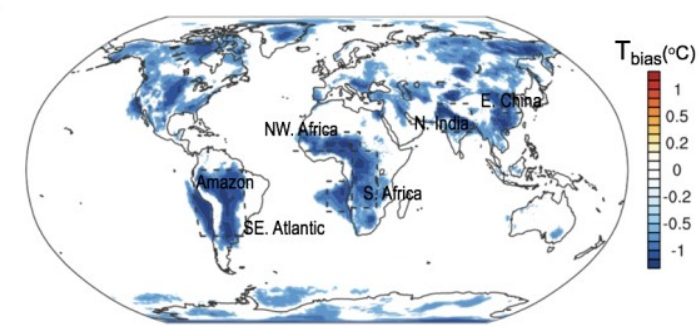

D

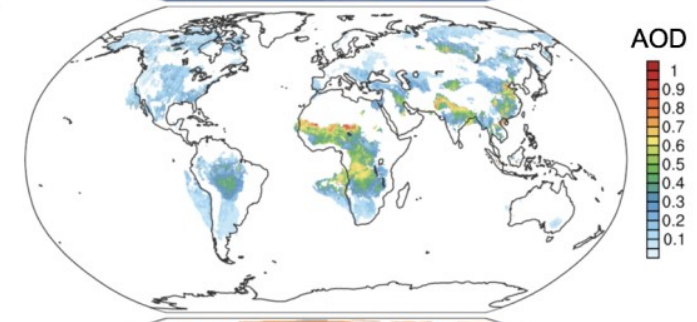

$\mathbf{F}$

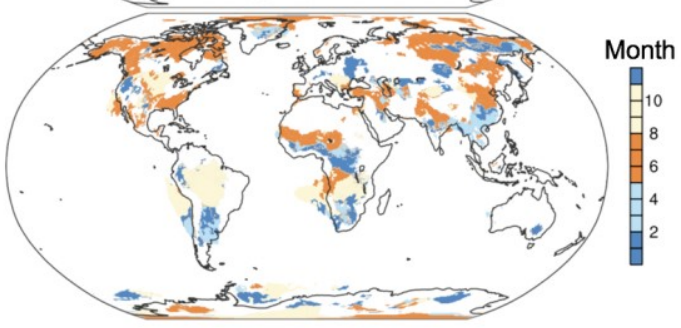

Fig. S5 Air temperature forecast bias in typical polluted regions. (A-B) Maximum positive and negative monthly temperature bias of GFS 24-hour forecast compared with GDAS analysis at 925 $\mathrm{hPa}$. Note that only regions with positive bias larger than $0.3^{\circ} \mathrm{C}$ or negative bias greater than -0.5 ${ }^{\circ} \mathrm{C}$ are plotted. (C-D) AOD distribution in corresponding month with maximum and minimum temperature forecast biases in (A) and (B). (E-F) Months with maximum and minimum temperature forecast bias corresponding to area shown in $(\mathbf{A})$ and $(\mathbf{B})$. 

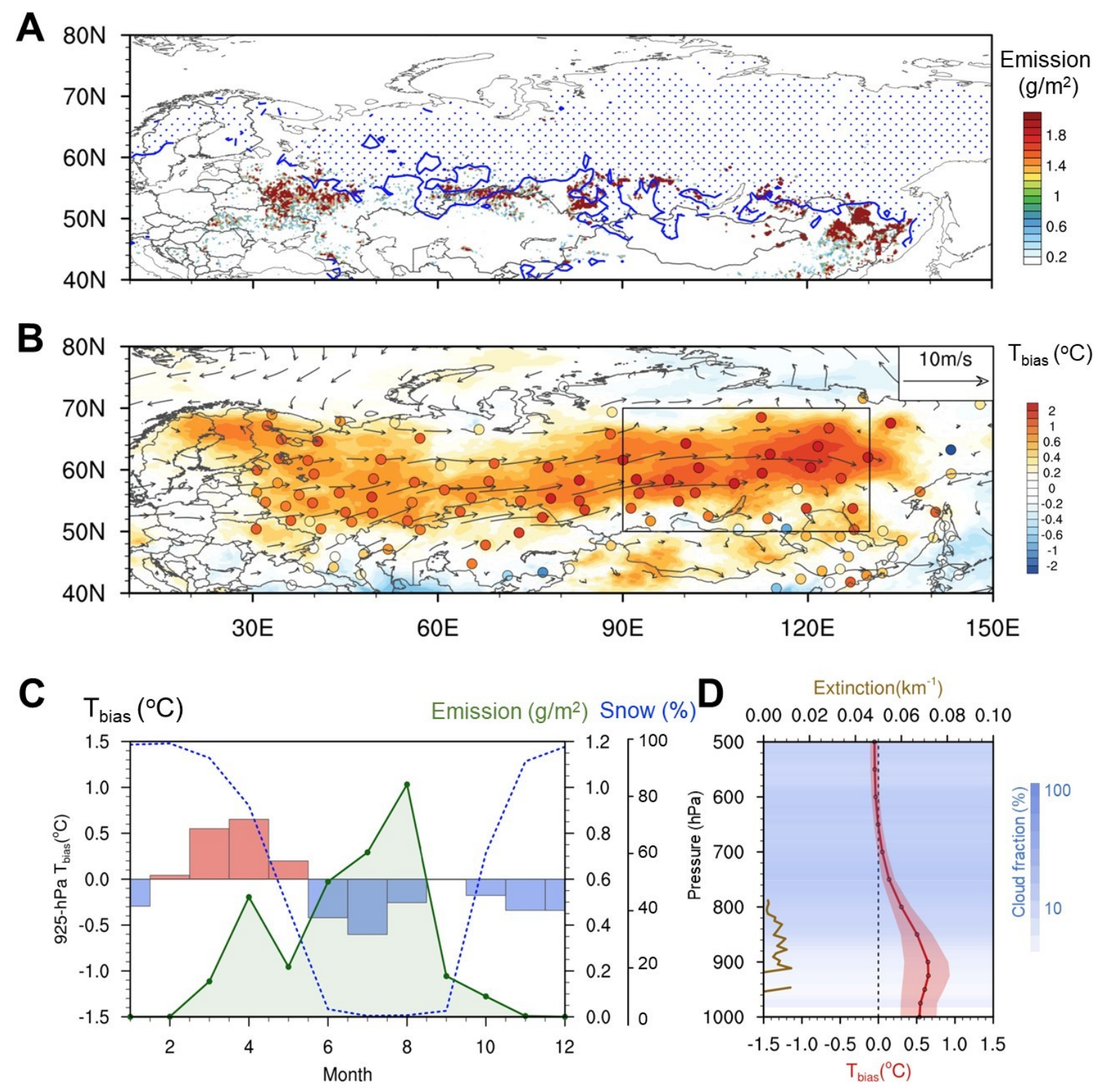

Fig. S6 Biomass burning and abnormal spring warming in E. Eurasia. (A) Spatial distribution of carbon emission from biomass burning, snow cover (fraction $>50 \%$ ) in April. (B) Spatial distribution of OMF air temperature biases of GFS 24-hour from GDAS analysis and radiosonde observations at $925 \mathrm{hPa}$ in Apirl. (C) Monthly variations of BB emission intensity in Eurasia, and $925 \mathrm{hPa}$ OMF temperature forecast bias and snow fraction in East Euroasia (black rectangle in B). (D) Vertical profile of temperature forecast bias, aerosol extinction and cloud fraction retrieved by CALIPSO in the corresponding region. 
A

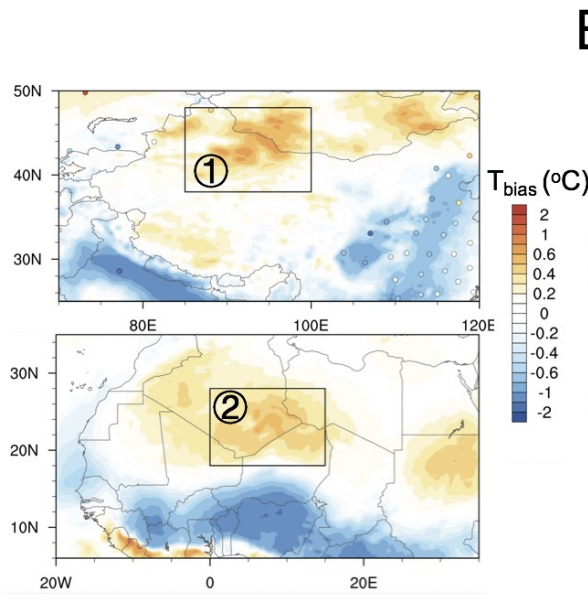

B

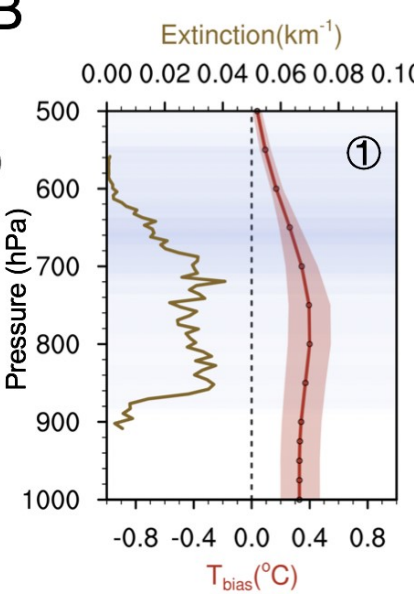

Extinction $\left(\mathrm{km}^{-1}\right)$ 0.000 .020 .040 .060 .080 .10

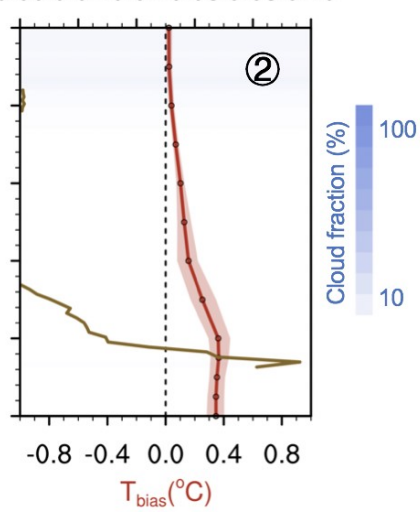

Fig. S7 Warming effect induced by dust. (A) Spatial distribution of air temperature bias between GFS 24-hour forecast and GDAS analysis at $925 \mathrm{hPa}$ in dust source regions in northern China (upper panel) and North Africa (lower panel) in March and January, respectively. (B) Vertical profile of temperature bias, aerosol extinction and cloud fraction retrieved by CALIPSO satellite in the corresponding regions in $(\mathbf{A})$. 


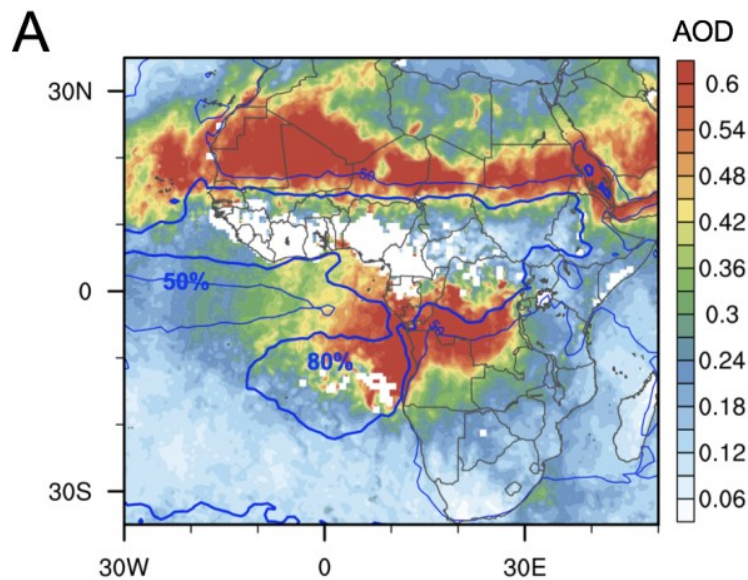

C

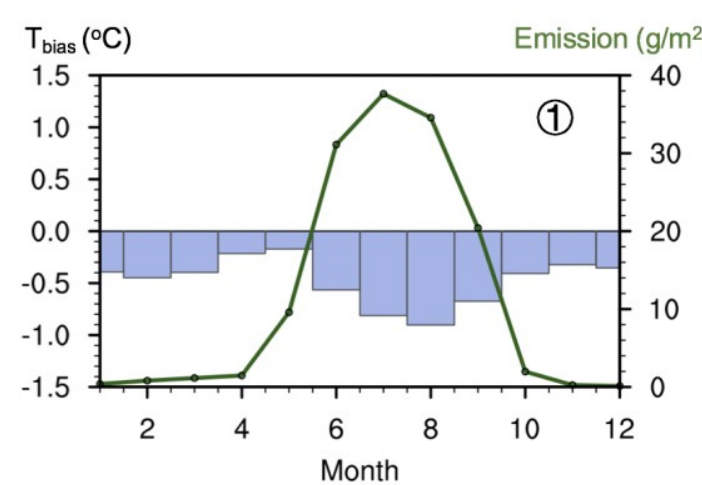

B

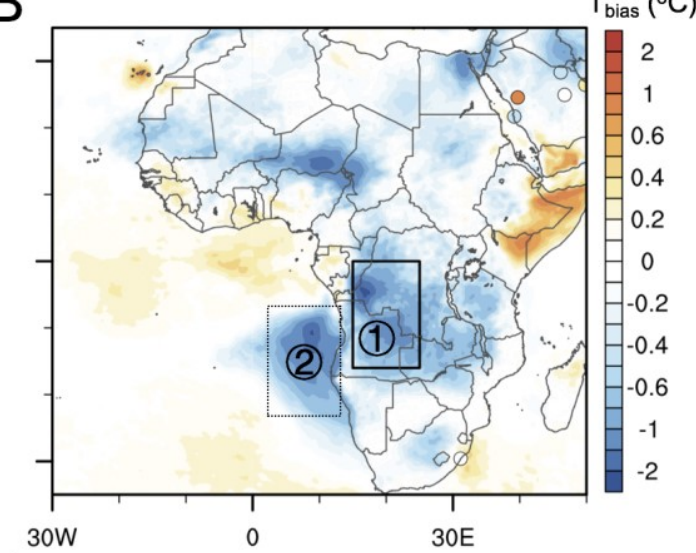

D

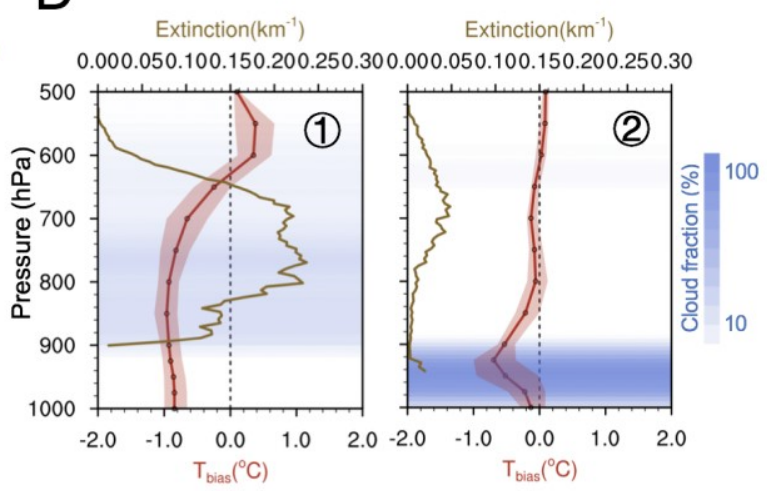

Fig. S8 Impact of African biomass burning on air temperature bias. (A) Spatial distribution of AOD and (B) biases of 925-hPa GFS 24-hr temperature from GDAS analysis in Africa and Southeast Atlantic. (C) Seasonal variations of the OMF temperature bias and BB emission intensity in southern Africa (solid rectangle in B). (D) Vertical profiles of temperature bias, aerosol extinction and cloud fraction retrieved by CALIPSO in South Africa (solid rectangle in B) and Southeast Atlantic (dash rectangle in B). 

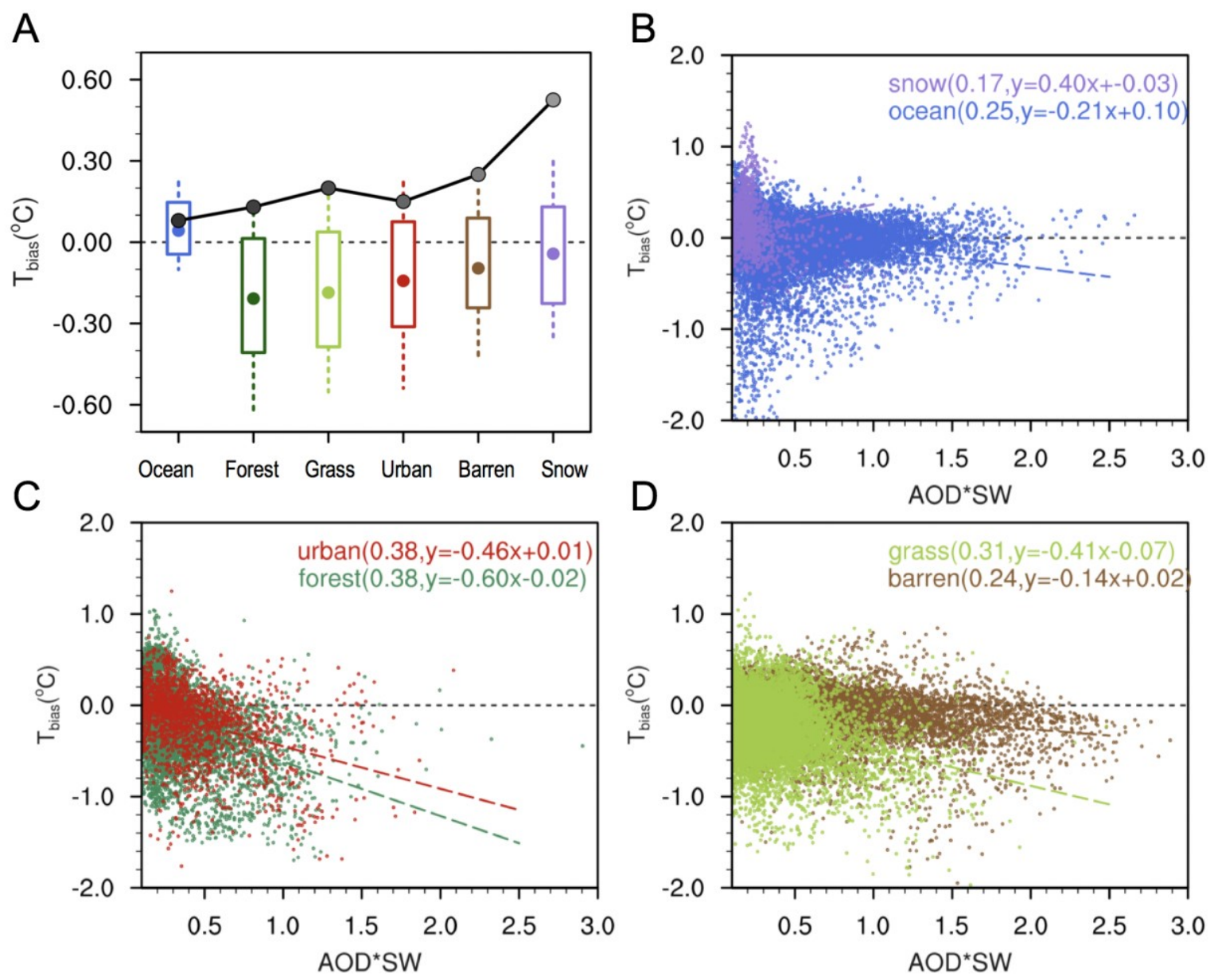

Fig. S9 Temperature forecast bias over different underlying surfaces. (A) Forecasted temperature bias over ocean, forest, grassland, urban and barren regions. Boxs present $25-75^{\text {th }}$ percentile range, and dash lines mark $10-90^{\text {th }}$ percentile range. Black circles show the averaged albedo values. (B-D) Scatter plots of forecasted temperature bias as a function of AOD $\times S W$ over different land covers. 


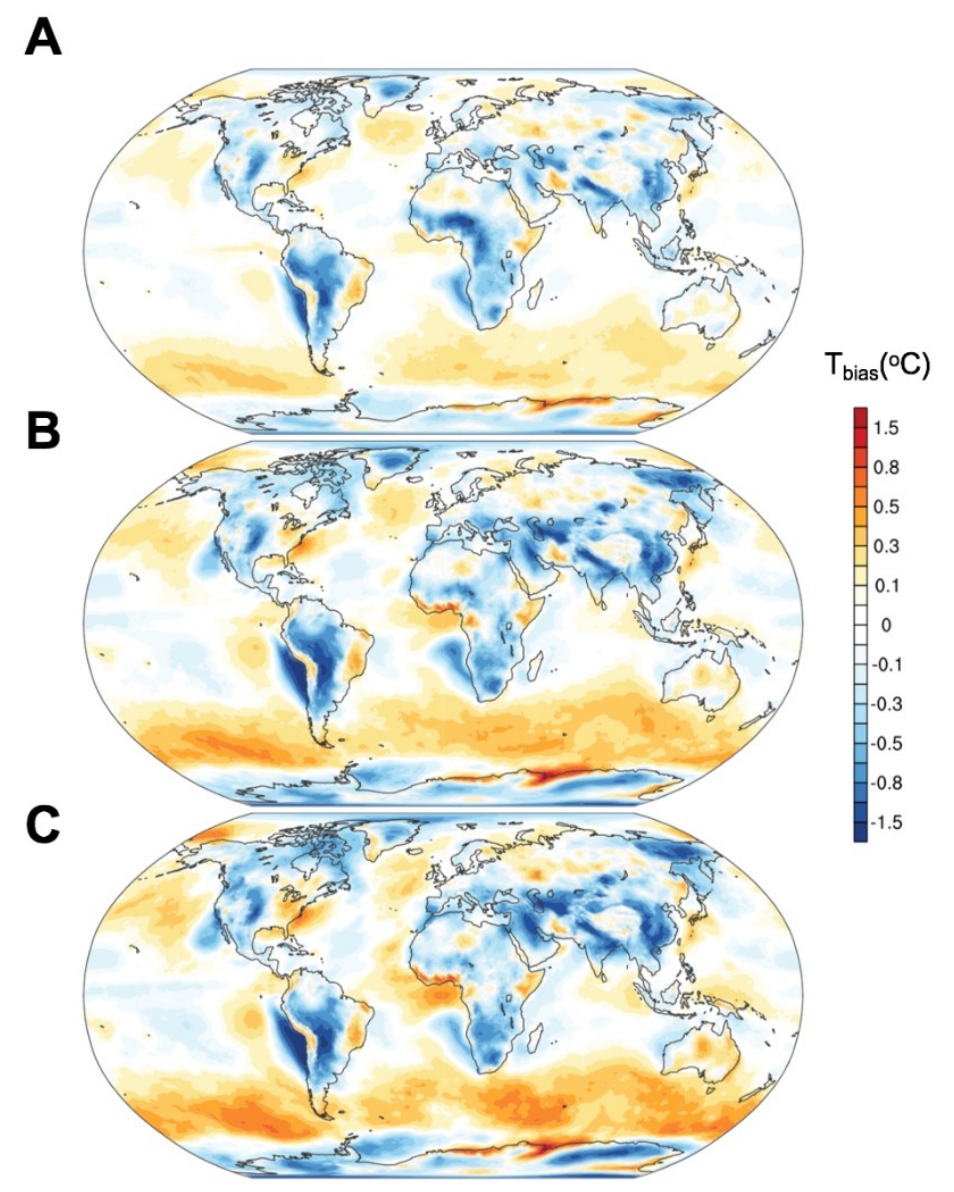

Fig. S10 Increasing temperature forecast bias with forecast time. Annual averaged OMF air temperature bias of GFS (A) 24-hour, (B) 72-hour, and (C) 120-hour forecast, compared with GDAS analysis at $925 \mathrm{hPa}$, respectively. 